\title{
Nonuniform but highly preferential stemflow routing along bark surfaces and actual smaller infiltration areas than previously assumed: A case study on European beech (Fagus sylvatica L.) and sycamore maple (Acer pseudoplatanus L.).
}

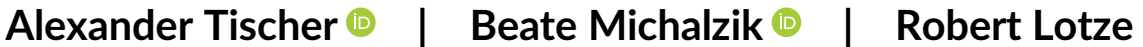

Institute of Geography, Friedrich-SchillerUniversität Jena, Jena, Germany

\section{Correspondence}

Alexander Tischer, Institute of Geography, Friedrich-Schiller-Universität Jena, Löbdergraben 32, 07743 Jena, Germany. Email: alexander.tischer@uni-jena.de

Funding information

Deutsche Forschungsgemeinschaft, Grant/ Award Number: CRC 1076 AquaDiva

\begin{abstract}
Canopy and tree morphology are assumed to play a significant role in modulating the amount of rainfall water during its routing throughout the vegetation and the nearsurface Critical Zone. One crucial point of research addresses the spatial extent of stemflow (SF) infiltration, because its concentration over small areas at the trunk base appears to affect the magnitude and timing of water and solutes input to the soil and hence amplify biogeochemical cycling. By a Brilliant Blue tracer experiment, we examined the flow patterns of SF water along the trunk surface of two broadleaved tree species (Fagus sylvatica and Acer pseudoplatanus) and the infiltration area the trunk base and down to $0.12-\mathrm{m}$ soil depth following natural rainfall events.

Our results point to highly preferential SF with smaller washed-off stem areas for sycamore maple $(\leq 15 \%)$ compared with European beech $(\leq 39 \%)$. The infiltration area is remarkably smaller than the basal area (BA), accounting for only $17 \%$ of the BA for beech and for $30 \%$ for maple. Differences in decolourized stem areas between the trees do not relate to the magnitude of infiltration areas at the soil surface, suggesting a strong effect of coarse root abundance and run-off properties on the funnelling of SF water.

In essence, our investigation exhibited that SF routing along bark surfaces and infiltration at the trunk base were spatially more concentrated than commonly assumed. The outcome of this study might contribute to our understanding on hydrological and biogeochemical interlinkages between the plant cover and the near-surface Critical Zone.
\end{abstract}

KEYWORDS

coarse roots, double funnelling, ecohydrological traits, precipitation partitioning, soil moisture

\section{1 | INTRODUCTION}

Forest landscapes significantly contribute to the functionality of the Earth's Critical Zone (CZ), which extends from the vegetation-

Alexander Tischer and Beate Michalzik contributed equally to the manuscript. atmosphere boundary down to the freshwater-bedrock interface (Guo \& Lin, 2016). Forests are characterized by spatially heterogeneous distributions of water, radiation and matter affecting the small-scale patterns of ecosystem processes such as productivity and element cycling (Spies, 1998). The understanding of how water dynamics and partitioning are shaped by plants is crucial to decipher 
CZ processes at the transition between the surface and subsurface environment. Major drivers inducing flux heterogeneities are morphological attributes of tree species and tree individuals as well as their spatial arrangement (Frischbier, Tiebel, Tischer, \& Wagner, 2019; Gersper \& Holowaychuk, 1971; Metzger, Schumacher, Lange, \& Hildebrandt, 2019; Spies, 1998). Altogether, heterogeneity in water, energy and nutrient abundance, and fluctuating driving factors are the rule and not the exception in forest ecosystems (Spies, 1998).

Rainfall partitioning into throughfall, stemflow (SF) and canopy interception is a crucial process in forest ecohydrology (Levia \& Germer, 2015). The partitioning and spatial redistribution create a persistent continuum of spots ranging from relatively dry to extraordinary wet spots at the soil surface (Metzger et al., 2017). Throughfall and SF form critical components of the hydrological and biogeochemical cycles of forest ecosystems, as they are the two hydrological pathways responsible for the transfer of precipitation and solutes from vegetative canopies to the soil. Although SF rarely accounts for $>10 \%$ of the incident rain, its concentration over small areas at the base of trunks appears to affect the magnitude and timing of water inputs to the soil and hence amplify biogeochemical cycling excessively (Carlyle-Moses et al., 2018; Levia \& Germer, 2015; van Stan \& Stubbins, 2018). After released from the trunk, SF contributes to subsequent water movement in the soil and along slopes (Spencer \& van Meerveld, 2016), and adds to groundwater recharge (Buttle, Toye, Greenwood, \& Bialkowski, 2014), hence connecting the surface and subsurface environment of the $\mathrm{CZ}$.

Both throughfall and SF amount and chemistry are the result of the interaction of different variables including meteorological conditions such as the amount and time profile of precipitation events (Dunkerley, 2014; Metzger et al., 2019) along with differences within and among tree species developing particular canopy and tree structures (Frischbier et al., 2019; Gersper \& Holowaychuk, 1971; Levia \& Germer, 2015; Metzger et al., 2019). Because of canopy exchange processes during precipitation and subsequent drainage across canopy and bark surfaces, throughfall and especially SF become enriched in elements, including micronutrients and macronutrients (Gersper \& Holowaychuk, 1971), as well as dissolved organic matter (Johnson \& Lehmann, 2006). Thus, SF generates elevated nutrient fluxes to the soil around the tree base and can create small-scale increases in nutrient concentrations (Johnson \& Lehmann, 2006) and can also accelerate soil acidification in zones of high SF input (Gersper \& Holowaychuk, 1971). These chemical shifts potentially result in different patterns of belowground space occupation as expressed by fine root distribution.

Though substantial amount of literature on throughfall and SF research is available, recent reviews on ecohydrology of forested ecosystems identified several key points of uncertainty where current knowledge is weak (Levia \& Germer, 2015). One of these crucial points for further research is the question of the spatial extent or the area of SF penetration into soils, that is, infiltration area (van Stan, 2019). Recent research that addresses the spatial extent of SF input to the soil by dye application or artificial water application assumes a homogeneous passage of rainfall water along the tree stem and consequently homogeneous infiltration rates around the tree base (Guo, Mount, Hudson, Lin, \& Levia, 2020; Liang, K'i, \& Mizuyama, 2011; Schwärzel, Ebermann, \& Schalling, 2012; Spencer \& van Meerveld, 2016). However, experiments on model trees and observations in the field support the idea of asymmetric or preferential flow of water along the stem-inducing variable and highly unpredictable infiltration areas at the trunk base (Dunkerley, 2014; Spencer \& van Meerveld, 2016). Current estimates on the infiltration area of SF vary substantially with areas ranging from $0.30-$ to $1.00-\mathrm{m}$ distance around the stem base (Schwärzel et al., 2012; Spencer \& van Meerveld, 2016; Tanaka, Taniguchi, \& Tsujimura, 1996; Voigt, 1960). Friesen (2020) listed infiltration areas between 0.01 and $11.83 \mathrm{~m}^{2}$ per tree with most of the studies showing infiltration areas $>0.40 \mathrm{~m}^{2}$. Because of its asymmetric or preferential flow routing, it is very likely that infiltration areas of SF are much smaller than currently estimated. For instance, Jackson, Wallace, and Ong (2000) stated: 'Observations made while stemflow was occurring suggested that in fact, the water reaching the soil by way of the trunk tended to infiltrate within a few centimeters from the base of the tree'. Deviations from above-mentioned assumptions on homogeneity of SF pathway may affect estimates of effective or active infiltration areas as an instrument to integrate SF in water budget models at higher spatial scales. Dye tracing or irrigation experiments generally observe the preferential flow of SF water on the surface of coarse and fine roots (Guo et al., 2020; Spencer \& van Meerveld, 2016), which adds to the concept of a 'double-funneling of water' (Johnson \& Lehmann, 2006; Schwärzel et al., 2012), supporting the idea of a restricted area of SF infiltration.

In the present case study, we tested the assumption of (1) homogeneous distribution of SF across the stem surface and (2) its homogeneous entry to the topsoil around the stem base of two tree individuals in juxtaposition. We argue that the clarification of these assumptions is important for further research that aims for the upscaling of SF fluxes to the ecosystem scale because it represents an overproportional high and potentially deep-reaching input pathway (Tanaka et al., 1996). In order to link SF input patterns to ecological relevant characteristics, we also investigated the question whether zones of 'high throughflow' (colour stained) are associated with high fine root abundances and low soil $\mathrm{pH}$.

We therefore conducted a colour tracer experiment with Brilliant Blue FCF (Flury \& Flühler, 1995) to identify flow patterns of SF water along the stem surface of two common, SF-generating broadleaved tree species (Fagus sylvatica L. and Acer pseudoplatanus L.) and to estimate the infiltration area at the trunk base and into the ground following natural rain events. Both tree species are representative for forest communities of Central Europe but differ in their ecological strategy of space occupation in forests with sycamore maple exhibiting a strong phototropism that results in stem curvatures. European beech is characterized by a straight stem due to the high shade tolerance and respective growth and thus is assumed to show different SF and infiltration patterns (according to literature cited in Friesen \& van Stan, 2019). 


\section{2 | METHODS}

\section{1 | Study site}

The investigation was conducted in the Hainich area, West Thuringia, Central Germany, forming part of the Hainich Critical Zone Exploratory (HCZE), which was established as an interdisciplinary research platform on subsurface biodiversity within the Collaborative Research Center (CRC) 'AquaDiva-Understanding the Links Between Surface and Subsurface Biogeosphere' (Küsel et al., 2016). The climate is characterized by a mean annual air temperature of $8.4^{\circ} \mathrm{C}$ and a mean annual precipitation of $547 \mathrm{~mm}$ (Unstrut valley, Bad Langensalza/Großwelsbach, for the period 1981-2010; www.dwd. de/cdc). The climate in the study area is characterized by a summer maximum of precipitation in particular due to the abundance of thunderstorms in this period ( $>60 \%$ of annual thunderstorms are during summer; www.dwd.de/cdc). The predominant soil type of the study area is formed by Calcaric Cambisol (Siltic) developed from carbonate rocks (German Triassic Muschelkalk formations) and Haplic Luivsol formed on Pleistocene Loess. The texture of the topsoil is characterized as a silt loam with $12-17 \%$ clay and $65-85 \%$ silt. The bulk density of the investigated topsoil ranges between 1.4 and $1.6 \mathrm{~g} \mathrm{~cm}^{-3}$.

\section{2 | Experimental set-up}

Within a beech-dominated broadleaved forest $\left(51^{\circ} 06^{\prime} 59.3^{\prime \prime} \mathrm{N}\right.$, $10^{\circ} 24^{\prime} 23.6^{\prime \prime} \mathrm{E}$ ), one dominant individual each of sycamore maple (A. pseudoplatanus L.) and European beech (F. sylvatica L.) was selected on base of similarity in tree dimensions and social positioning. The diameter at breast height (DBH) for maple was $0.42 \mathrm{~m}$ and that of beech was $0.42 \mathrm{~m}$, resulting in basal areas (BAs) of 0.1397 and
$0.1368 \mathrm{~m}^{2}$, respectively. Both trees are among the $10 \%$ most dominant individuals, whereas $70 \%$ of the trees show DBH $<0.25 \mathrm{~m}$. The horizontal crown extensions measured by crown mirror and tape measure, bark roughness according to Barbier, Balandier, and Gosselin (2009), and coverage of moss cushions are listed in Table 1. The projected crown area amounted to $33.0 \mathrm{~m}^{2}$ for maple and $33.2 \mathrm{~m}^{2}$ for beech. Tree trunk leans were measured on the digital pictures for the cardinal direction with the highest angle from the vertical using an online protractor (https://www.ginifab.com/feeds/angle_measurement/). For maple trunk lean, the angle amounted to $14^{\circ}$ towards south, whereas for beech, the angle amounted to $5^{\circ}$ towards north.

The stems of the two trees were manually stained by highly concentrated $\left(20 \mathrm{~g} \mathrm{~L}^{-1}\right)$ Brilliant Blue (Erioglaucin A, Omikron, Germany) solution from above the root base up to $1.5-\mathrm{m}$ height. Brilliant Blue is a synthetic, resoluble, nontoxic food dye with a high colour intensity that is suitable to visualize and analyse flow patterns along plant and soil surfaces, forming sharp, well-separated flow fronts (Flury \& Flühler, 1995). The stained area also included zones of moss cushions (mainly formed by Brachythecium spp. and Hypnum spp.) (Figure 2). Coverage of moss cushions is listed in Table 1. By the 'passive dye application' technique reported here, the complete trunk area was dye stained in advance by a smooth paste of Brilliant Blue using a brush, and SF patterns along the trunk surface and soil infiltration areas were tracked and visually quantified following five natural rain events. This approach differs from common colour tracer experiments (Liang et al., 2011; Schwärzel et al., 2012; Spencer \& van Meerveld, 2016), where stems are actively and homogeneously sprinkled with relatively large amounts of colour tracer solution and immediate induction of homogeneous SF.

Additional variables were assessed in order to characterize rainfall events and partitioning. For the estimation of throughfall volumes, eight throughfall collectors (area per collector $0.0314 \mathrm{~m}^{2}$ ) were installed around each tree in $0.5-\mathrm{m}$ distance to the trunk along the four cardinal and the four intercardinal directions and one additional

TAB LE 1 Properties of the selected sycamore maple (Acer pseudoplatanus L.) and European beech (Fagus sylvatica L.) individuals from the Hainich region in Central Germany

\begin{tabular}{|c|c|c|c|c|c|c|}
\hline $\begin{array}{l}\text { Cardinal } \\
\text { direction }\end{array}$ & \multicolumn{6}{|l|}{ Tree species } \\
\hline $\mathrm{N}$ & 39.7 & $\begin{array}{c}\text { Smooth/scaly/partly } \\
\text { fissured }\end{array}$ & 5.75 & 41.6 & Smooth & 3.10 \\
\hline$S$ & 45.0 & $\begin{array}{c}\text { Scaly/smooth/partly } \\
\text { fissured }\end{array}$ & 6.15 & 54.9 & Smooth & 4.20 \\
\hline W & 0.0 & Fissured/smooth & 2.75 & 70.0 & Smooth & 4.30 \\
\hline
\end{tabular}

aMoss cover was estimated using INKSCAPE Version 0.92 .4 (https://www.inkscape.org) by using the 'Visualize path' function and subsequent pixel area determination.

${ }^{\mathrm{b}}$ Classification of bark roughness according to Barbier et al. (2009).

'The horizontal crown extensions along the four cardinal directions were measured using a crown mirror, and the distance to the tree trunk was measured using a tape measure. 
sampler per tree in a canopy gap. To relate amounts and timing of bulk precipitation to throughfall volumes and soil moisture response, precipitation data (in 10-min resolution) were obtained from the nearby weather station Heuberg $\left(51^{\circ} 06^{\prime} 33.8^{\prime \prime} \mathrm{N}, 10^{\circ} 24^{\prime} 52.0^{\prime \prime} \mathrm{E}\right)$ (Figure 1).
In order to test whether soil moisture in the surrounding of the trees was affected by throughfall or by SF input, soil moisture measurements were conducted. Soil moisture was estimated by eight frequency domain reflectometry (FDR, ThetaProbe ML2x,
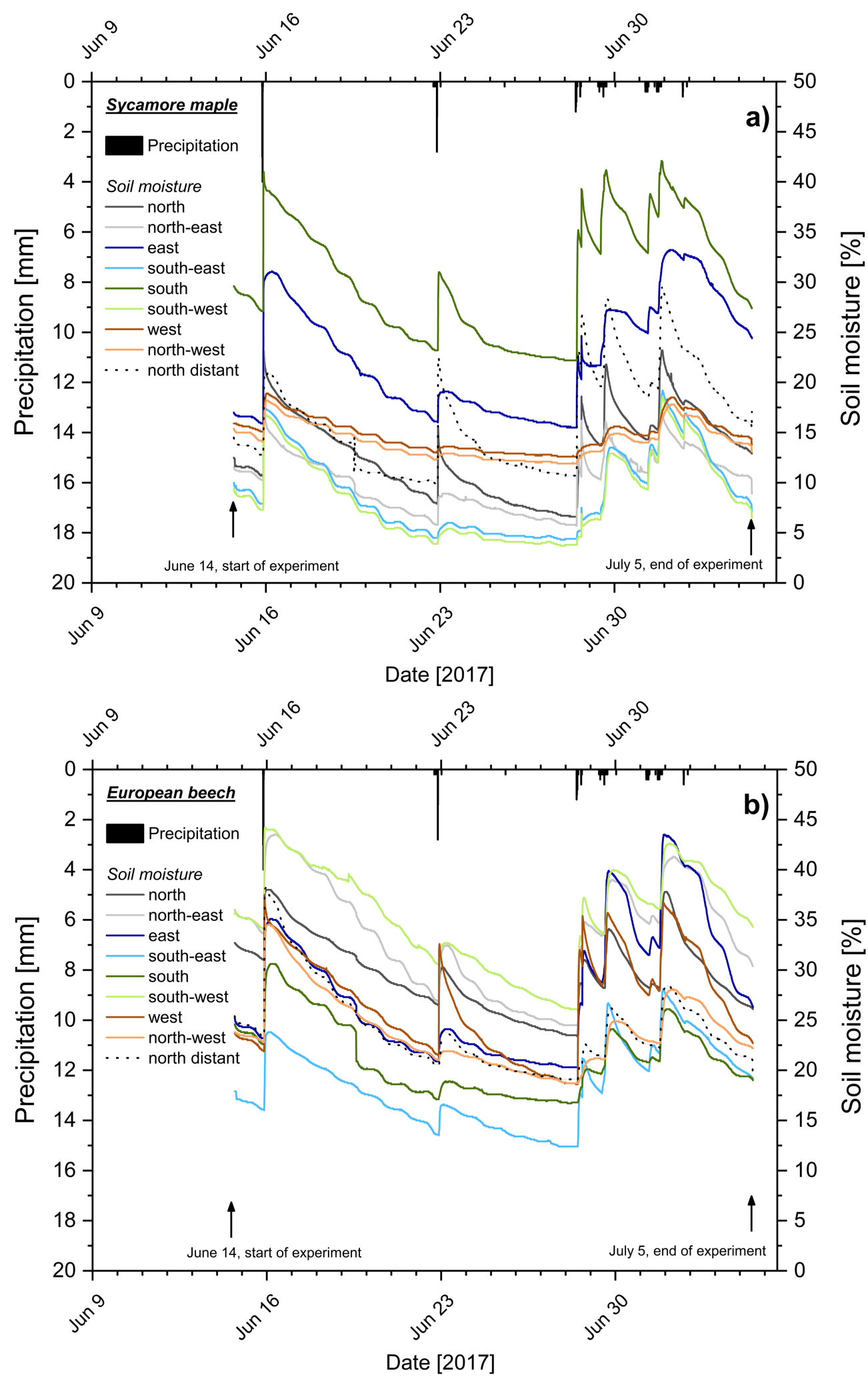

FIGURE 1 Precipitation data (in 10-min resolution) from the weather station Heuberg (left $Y$ axis) and soil moisture development (in 10-min resolution) derived from eight frequency domain reflectometry sensors in 0.2- $\mathrm{m}$ distance to the trunk along the four cardinal and the four intercardinal directions (right $Y$ axis), and one additional FDR sensor in 0.4-m distance to the trunk in northern direction ('north distant'), for sycamore maple (Acer pseudoplatanus L.) (top) and European beech (Fagus sylvatica L.) (bottom) 
Delta-T Devices, Cambridge, England) sensors per tree installed in 0.1-m depth and in 0.2-m distance to the trunk along the four cardinal and the four intercardinal directions. One additional FDR sensor was located in northern direction in 0.4-m distance to the trunk. Recording of soil moisture data spanned 4 weeks from June 10 to July 10, 2017, in 10-min resolution (Figure 1). The experimental set-up was finalized on June 14, 2017. The first throughfall samples were collected on June 19 following a rainfall event on June 15. After a period of light to moderate rainfall events between June 20 and July 5 , the second collection of throughfall samples was performed from July 5 to 7 in concert with dye imaging and soil sampling.

\subsection{Imaging and analysing of decoloured trunk areas}

For imaging, the trunk area was vertically separated into four sectors by strings matching the four cardinal directions in order to avoid overlapping and thus double counting of stem surface area. The pictures taken (Canon PowerShot SX50 HS) from each sector were analysed by Adobe Photoshop CS5 (Version 12.0.0). Photographs were manually processed, and no specific colour channel was selected for further processing. In particular, for the litter layer, manually processing was necessary to distinguish surfaces affected by SF (highly defined and sharp edges) from those affected by splash (diffuse colouration of litter). This splash apparently originated from water being splashed-back from the stem area as described in Section 3. For better distinguishability, regions that were washed off by SF water and hence discoloured were manually marked in red. For areal standardization, a black square of $100 \mathrm{~cm}^{2}$ with a defined number of pixels formed part of each picture (Figure 2). For areal quantification of discoloured areas, both black (from the standardization square) and red pixels were counted, related to each other and converted into centimetre square. The moss-covered area was excluded from the assessment because here it was impossible to clearly identify regions of discolouration; thus, we may have underestimated SF-active bark surface in some cases. Images were taken before and after dye staining as well as after the first and second cohort of rainfall events concurrently to throughfall sampling.

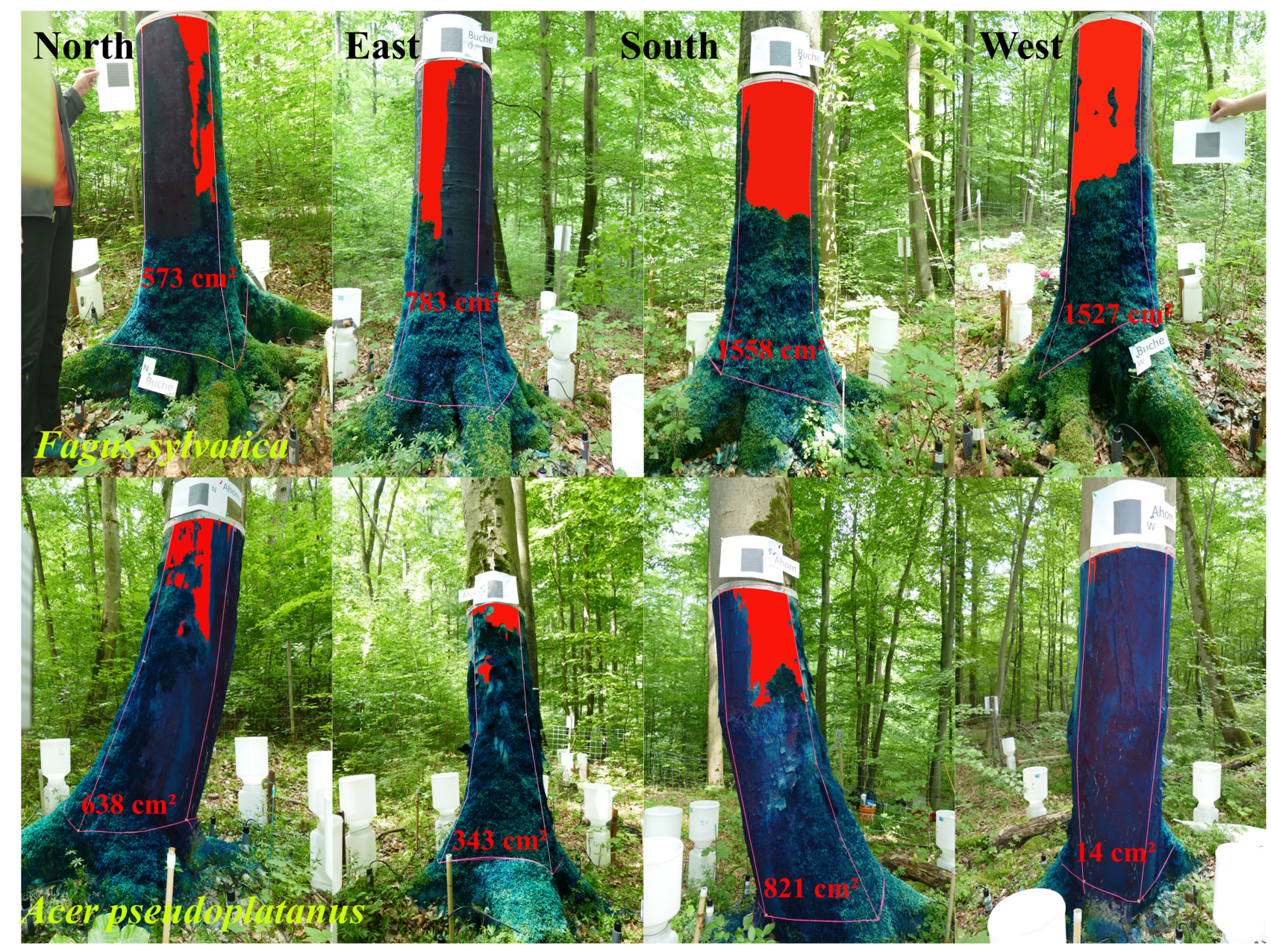

FIGURE 2 Distribution of stemflow for European beech (Fagus sylvatica L., top row) and sycamore maple (Acer pseudoplatanus L., bottom row). Brilliant Blue-stained stem areas that were discoloured by stemflow wash-off were marked by red colour via photo-processing (Adobe Photoshop (S5) and afterwards extensively quantified. Photo credits: Robert Lotze 


\subsection{Imaging of dye-stained soil areas}

In a 0.2-m-wide corridor around each trunk, the ground was horizontally separated into eight sectors by strings corresponding to the four cardinal and intercardinal directions (Figure 2) in order to avoid overlapping and thus double counting of surface area. Along four depth zones encompassing the forest floor and the mineral soil in $0-$ to 4-, 4- to 8-, and 8- to 12-cm depth increments, the soil surface was carefully excavated and pictures for imaging were taken. Similar to the discolouration assessment of the trunks, areal standardization within each sector and for each soil depth was facilitated by a black square of $100 \mathrm{~cm}^{2}$ with a defined number of pixels, which were related to the pixel counts of the image-processed red areas.

\section{5 | Fine root measurements and soil $\mathrm{pH}$}

Within each sector and along the four depth zones, the forest floor material and the soil were completely removed and separated into dyed and undyed material $(8$ sectors $\times 4$ soil depths $\times 2$ dyed/undyed $=64$ samples per tree), respectively. The forest floor and soil material were dried at $50^{\circ} \mathrm{C}$. To allow for fine soil $(<2 \mathrm{~mm})$, coarse soil $(>2 \mathrm{~mm})$ and fine root separation, the mineral soil was sieved to $<2 \mathrm{~mm}$ and roots were sorted out manually.

The $\mathrm{pH}\left(\mathrm{CaCl}_{2}\right)$ of dyed and undyed forest floor samples was measured in a $10: 1$ slurry of $25 \mathrm{ml}$ of $0.01-\mathrm{M} \mathrm{CaCl}_{2}$ solution and $2.5 \mathrm{~g}$ of sample. Soil $\mathrm{pH}$ in dyed and undyed mineral fine soil samples was determined in a $2.5: 1$ slurry of $25 \mathrm{ml}$ of $0.01-\mathrm{M} \mathrm{CaCl}_{2}$ solution and $10 \mathrm{~g}$ of sample. All samples were shaken for $6 \mathrm{~min}$ on an overhead shaker (Reax 2, Heidolph Instruments, Germany) followed by a settle period of $0.5 \mathrm{~h}$, another manual shaking and finally allowed to settle for $0.5 \mathrm{~h}$ before $\mathrm{pH}$ was measured by a glass $\mathrm{pH}$ electrode (SenTix 41, WTW GmbH, Germany). In a laboratory assay, we found no evidence for a change in $\mathrm{pH}$ after application of Brilliant Blue to unstained samples (paired $t$ test: $t=-1.14, p=0.2721$ ).

\subsection{Statistical analysis}

Observations among stem and soil sectors for each soil depth were pooled in order to calculate tree-wise median, minimum and maximum in tables as well as in box-whisker plots (including arithmetic mean). The number of observations for the stem of each tree amounts to $n=4$ and those for each soil depth interval to $n=8$.

\section{3 | RESULTS AND DISCUSSION}

\section{1 | Precipitation, throughfall amounts and soil moisture near tree trunks}

The precipitation event on June 15 recorded at the nearby climate station amounted to $7.80 \mathrm{~mm}$ (Figure 1). Mean throughfall volumes from June 19 around the trunk ranged between 5.28 and $7.96 \mathrm{~mm}$ with a median of $7.07 \mathrm{~mm}$ for maple and 8.02 and $10.50 \mathrm{~mm}$ with a median of $9.15 \mathrm{~mm}$ for beech. Cumulative precipitation volumes of the rain events occurring between June 20 and July 5 amounted to $15.40 \mathrm{~mm}$, corresponding to throughfall volumes of 14.32 to $19.74 \mathrm{~mm}$ with a median of $16.36 \mathrm{~mm}$ for maple and 13.85 to $16.87 \mathrm{~mm}$ with a median of $15.45 \mathrm{~mm}$ for beech. As compared with the study of Metzger et al. (2017), these events can be considered as moderate rainfall events $(3-10 \mathrm{~mm})$ and are representative for

TAB LE 2 Initial (minimum) preevent, (maximum) postevent water content (WC), elapsed time (in minutes) after maximum postevent WC occurred and absolute differences in WC for three rain events of $7.8 \mathrm{~mm} \mathrm{~h}^{-1}$ (June 15), $4.6 \mathrm{~mm} \mathrm{~h}^{-1}$ (June 22) and $4.2 \mathrm{~mm} \mathrm{~h}^{-1}$ (June 28) under sycamore maple (Acer pseudoplatanus L.) and European beech (Fagus sylvatica L.)

\begin{tabular}{|c|c|c|c|c|c|c|c|c|c|}
\hline $\begin{array}{l}\text { Event } \\
\text { date/rainfall } \\
\text { amount }\end{array}$ & & \multicolumn{8}{|c|}{ Tree species } \\
\hline 15.06.2017 & Minimum & 7.3 & 16.9 & +3.8 & 40 & 16.0 & 23.8 & +7.0 & 40 \\
\hline $7.6 \mathrm{~mm} \mathrm{~h}^{-1}$ & Median & 12.7 & 21.0 & +9.6 & 110 & 23.2 & 37.5 & +10.1 & 160 \\
\hline 22.06.2017 & Minimum & 3.9 & 5.4 & +0.5 & 70 & 13.5 & 16.6 & +0.9 & 110 \\
\hline \multirow[t]{2}{*}{$4.6 \mathrm{~mm} \mathrm{~h}^{-1}$} & Maximum & 23.2 & 31.0 & +12.6 & 560 & 30.6 & 32.7 & +10.4 & 450 \\
\hline & Median & 9.9 & 13.6 & +2.9 & 250 & 21.0 & 24.1 & +3.2 & 350 \\
\hline 28.06.2017 & Minimum & 3.8 & 4.6 & +0.5 & 30 & 12.4 & 17.6 & +0.6 & 70 \\
\hline
\end{tabular}

Note: Average wind speed during the selected rain events was $2.4,1.9$ and $1.2 \mathrm{~m} \mathrm{~s}^{-1}$, respectively. Maximum wind speed was 4.0 , 3.3 and $2.3 \mathrm{~m} \mathrm{~s}^{-1}$, respectively. 
the rainfall events during summer in the study area. During both events, some collectors exhibited higher amounts of throughfall than in the open area (medians are also higher than open area precipitation), indicating the occurrence of dripping points, which led to throughfall addition underneath the canopies of both trees (Metzger et al., 2017). The order of TF volumes generated by the trees varies between events, suggesting effects of rainfall intensity, wind speed or canopy storage capacity during the observation period (Frischbier et al., 2019).

Most of the throughfall solutions collected at June 19 exhibited different intensities of Brilliant Blue, which apparently originated from water being splashed-back from the stem area. This 'splash effect' was more pronounced for maple (darker blue for six out of eight samplers) than for beech (light blue for five out of eight samplers). This indicates that SF water can also affect locations some decimetres away from the stem. However, the quantity and spatial extent of this 'splash effect' could not be evaluated by our study.

To test for differences in soil moisture development between maple and beech following rain events, we selected moderate $(\geq 2.5$ to $<7.6 \mathrm{~mm} \mathrm{~h}^{-1}$ of open area rainfall) to heavy $\left(>7.6\right.$ to $<50 \mathrm{~mm} \mathrm{~h}^{-1}$ ) rain events occurring over the course of the experiment. We identified three rain events of $7.8 \mathrm{~mm} \mathrm{~h}^{-1}$ (June 15), $4.6 \mathrm{~mm} \mathrm{~h}^{-1}$ (June 22) and $4.2 \mathrm{~mm} \mathrm{~h}^{-1}$ (June 28) (Figure 1), for which we calculated the absolute and relative increase in soil moisture between the initial (preevent) and top postevent soil moisture as well as the elapsed time (in minutes) of its occurrence (Table 2). Across all three rain events,
FIGURE 3 Distribution and areal extension of Brilliant Blue in the organic layer and in four mineral soil depths around the trunk base of sycamore maple (Acer pseudoplatanus L.) for northern (left) and western (right) sections. Brilliant Blue-stained surface is represented as red-coloured area. Photo credits: Robert Lotze

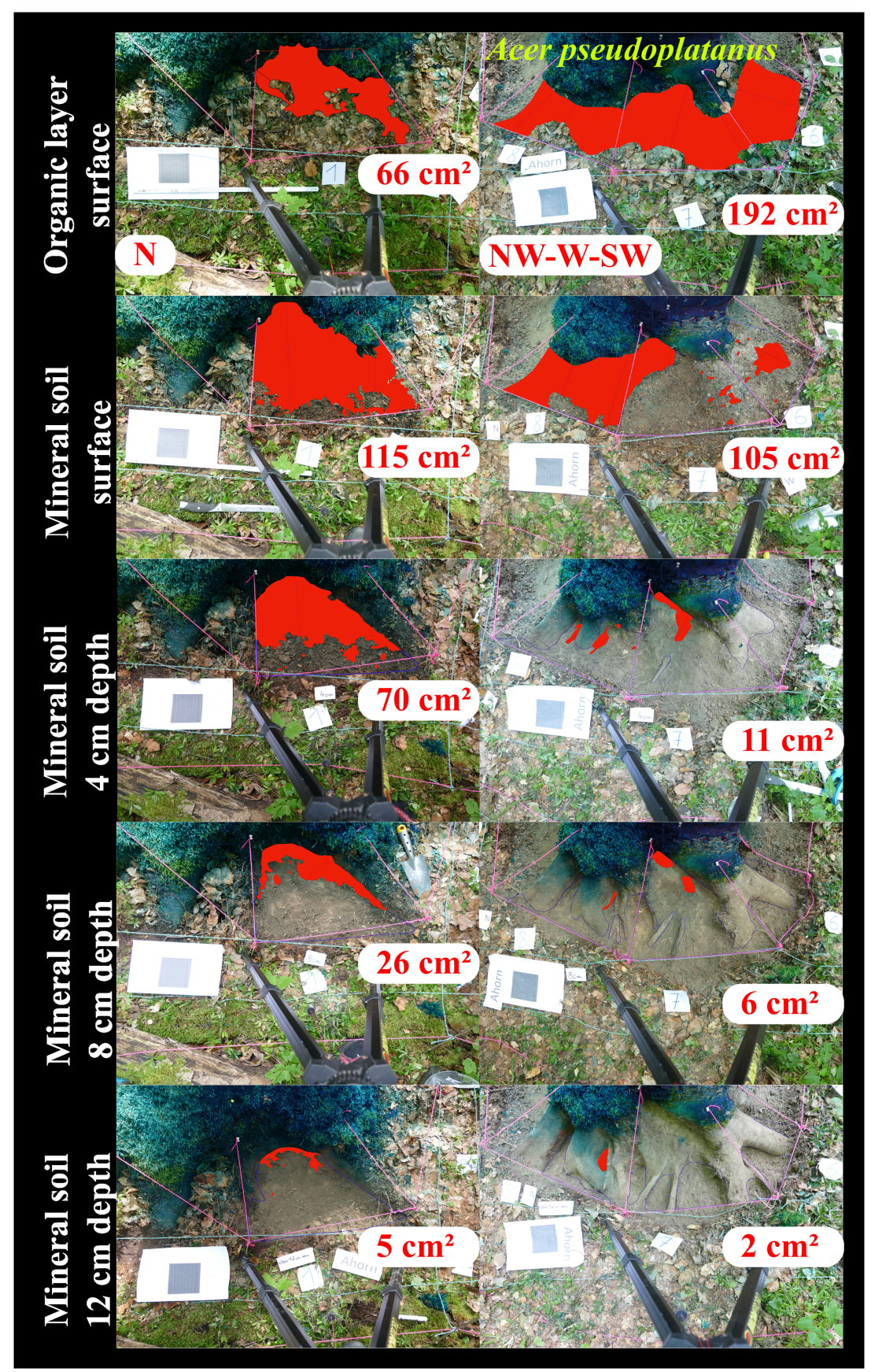


preevent water content (WC) averaged across eight sensors per tree were about two times lower for maple than for beech, eventually indicating a higher water uptake or faster drainage in the surrounding of the maple tree. Mean absolute increases in soil moisture following rain events were similar between both trees, indicating comparable amounts of input by TF. This is in agreement with the results of the respective TF measurements in concert with similar soil moisture values of the sensor in 0.4-m distance (Figure 1) and suggests that topsoil moisture at a distance of $0.2 \mathrm{~m}$ to the tree trunk was mainly driven by TF and not by SF input. Metzger et al. (2017) found TFdriven soil moisture patterns within a distance of $1.2 \mathrm{~m}$ to tree stems. The time elapsed until the maximum WC was reached took 50 to 100 min longer for beech than for maple, suggesting longer residence times of rainfall water within the beech canopy. This pattern might be related to the higher leaf area index and hence higher canopy storage capacity and differences in branch angles of beech (Frischbier et al., 2019). Figure 1 corroborates the shorter response time of soil moisture under maple (Figure 1a) as shown by the sharper peaks

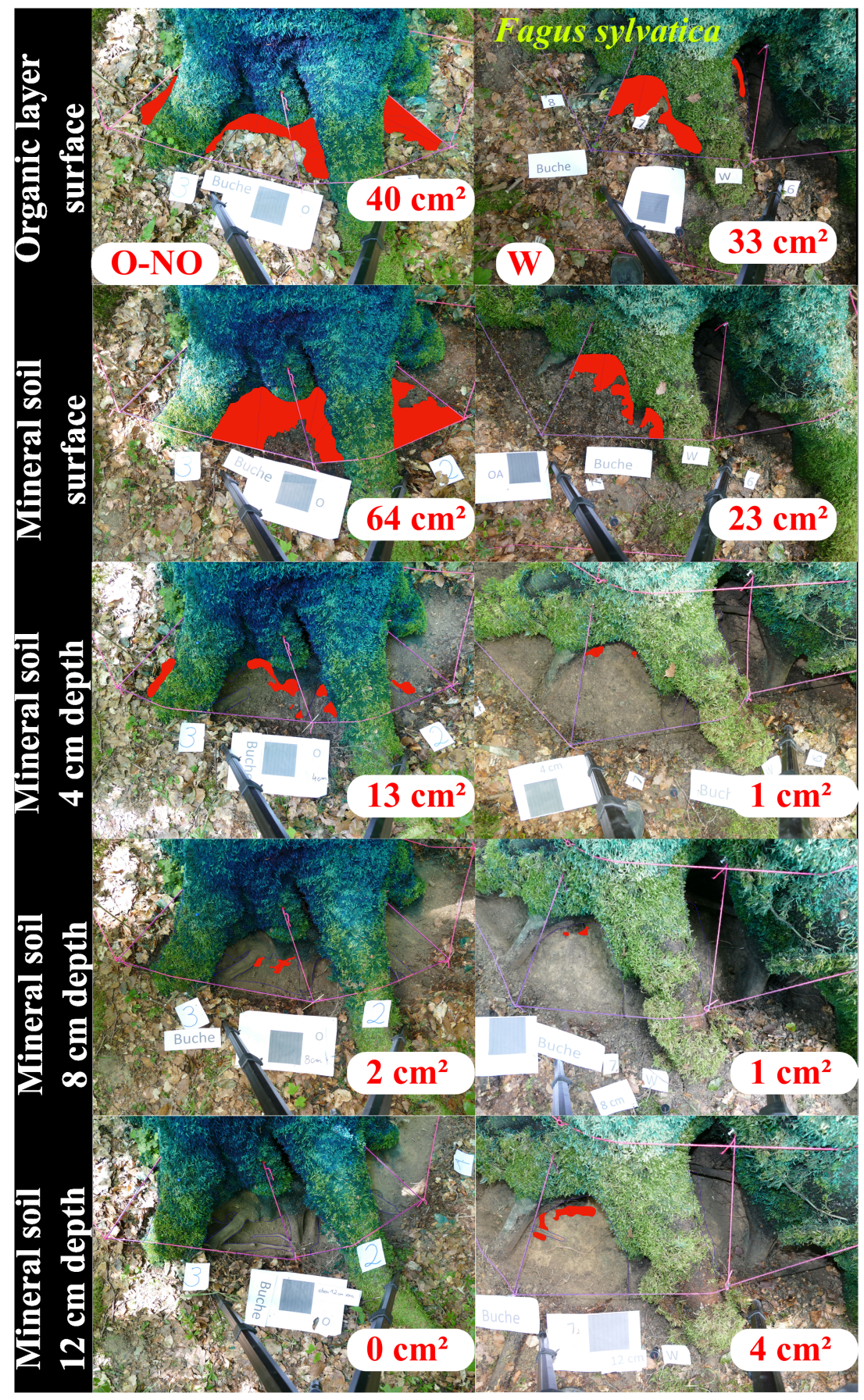

FIGURE 4 Distribution and areal extension of Brilliant Blue in the organic layer and in four mineral soil depths around the trunk base of European beech (Fagus sylvatica L.) for northeastern (left) and western (right) sections. Brilliant Blue-stained surface is represented as redcoloured area. Photo credits: Robert Lotze 
following moderate to heavy rain events and steeper declining graphs compared with beech (Figure 1b).

\section{2 | Imaging and quantification of SF pathways on the trunk}

For beech, some surface areas along the trunk were almost completely discoloured by SF (Figure 2 top row, south and west), whereas others in the transition zone between north to east (NE) direction were incompletely or less flushed. The phototropically growing maple tree revealed a pronounced stem curvature inducing a clear flow pattern with zones of intensified flow (Figure 2 bottom row, north and south) and zones without flow (Figure 2 bottom row, west). Generally, beech exhibited larger washed-off areas by SF $\left(0.4441 \mathrm{~m}^{2}\right)$ than maple $\left(0.1816 \mathrm{~m}^{2}\right)$, which supply evidence for larger SF rates as well (Metzger et al., 2019). Both tree individuals have equal DBH and canopy projection area (both traits are allometrically linked); differences in SF yield might be related to branch angles and other canopy traits (Friesen \& van Stan, 2019). In particular, for small and medium rainfall events, it is likely that beech generated approx. 2-fold higher SF amounts than maple (according to literature cited in Friesen \& van Stan, 2019). As a rough estimate, it is assumed that $13 \%$ of gross precipitation was partitioned into beech SF, whereas $6 \%$ was partitioned into SF of maple, resulting in total SF yields of $33.5 \mathrm{~L}$ for beech and $15.4 \mathrm{~L}$ for maple for the precipitation event of June 15 , and for the projected canopy area of approx. $33 \mathrm{~m}^{2}$. In case of maple, between $1 \%$ and $15 \%$ (median $=8 \%$ ) from each of the individual areas of the four stem sectors were washed off, whereas corresponding values for beech ranged between $12 \%$ and $39 \%$ with a median of $26 \%$. These observations highlight the occurrence of SF pathways or asymmetric SF along the tree trunk. Such asymmetric SF is likely related to canopy structure, branch distribution and angles, as well as to stem curvature and leaning (Gersper \& Holowaychuk, 1971; Levia \& Germer, 2015). Directions with larger washed-off areas are likely those with longer horizontal crown extension, in particular for maple.

\subsection{Identification of SF infiltration areas at the trunk base and into the ground}

For both tree species, the maximum distribution of Brilliant Bluestained ground areas occurred at the surface of the forest floor (sum of dyed area: maple $=0.04144 \mathrm{~m}^{2}$; beech $=0.02262 \mathrm{~m}^{2}$ ) and at the surface of the mineral soil (soil $0 \mathrm{~cm}$ : maple $=0.03696 \mathrm{~m}^{2}$; beech $=0.02002 \mathrm{~m}^{2}$ ) (Figures 3-6), representing 30\% of the BA $\left(0.1397 \mathrm{~m}^{2}\right)$ for maple and $17 \%\left(0.1368 \mathrm{~m}^{2}\right)$ for beech. The extension of dyed areas rapidly decreased with increasing soil depth (Figures 3-6). These patterns point to smaller active infiltration areas of SF as compared with calculations referring to the BA of trees or the canopy projection area. The variability in Brilliant Blue-stained areas at the surface of the forest floor and the soil was higher for maple than for beech (Figure 6). Based on the above roughly estimated SF yields, infiltration intensity is approx. fourfold higher for beech than for maple (twofold higher SF but half of the infiltration area).

The average distance of the colour-stained forest floor areas from the tree trunk ranged between 0.07 and $0.23 \mathrm{~m}$ with a median of $0.13 \mathrm{~m}$ for maple and between 0.02 and $0.12 \mathrm{~m}$ with a median of $0.06 \mathrm{~m}$ for beech (Figure 7). The colour pattern found on the organic layer under maple (mainly western directions) did not follow the SF pattern identified at the trunk surface, which was most pronounced for northern, eastern and southern directions. Whereas for beech, trunk regions of high SF were in good accordance to those found for the forest floor. However, in the mineral soil, these relations tailed off.
FIGURE 5 Sum of Brilliant Blue-dyed areas at the surface of the organic layer (forest floor) and the four mineral soil depths around the trunk base of sycamore maple (Acer pseudoplatanus L.) and European beech (Fagus sylvatica L.)

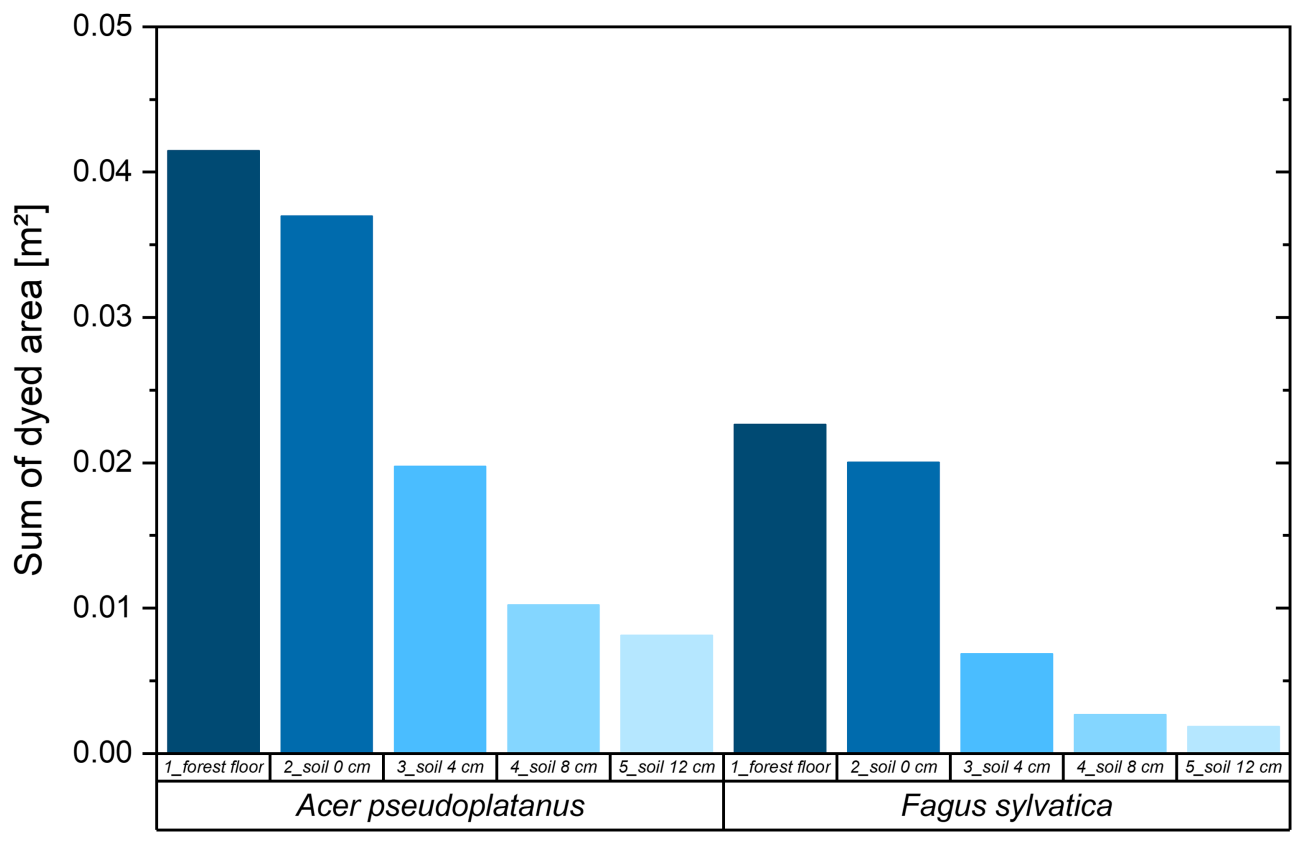




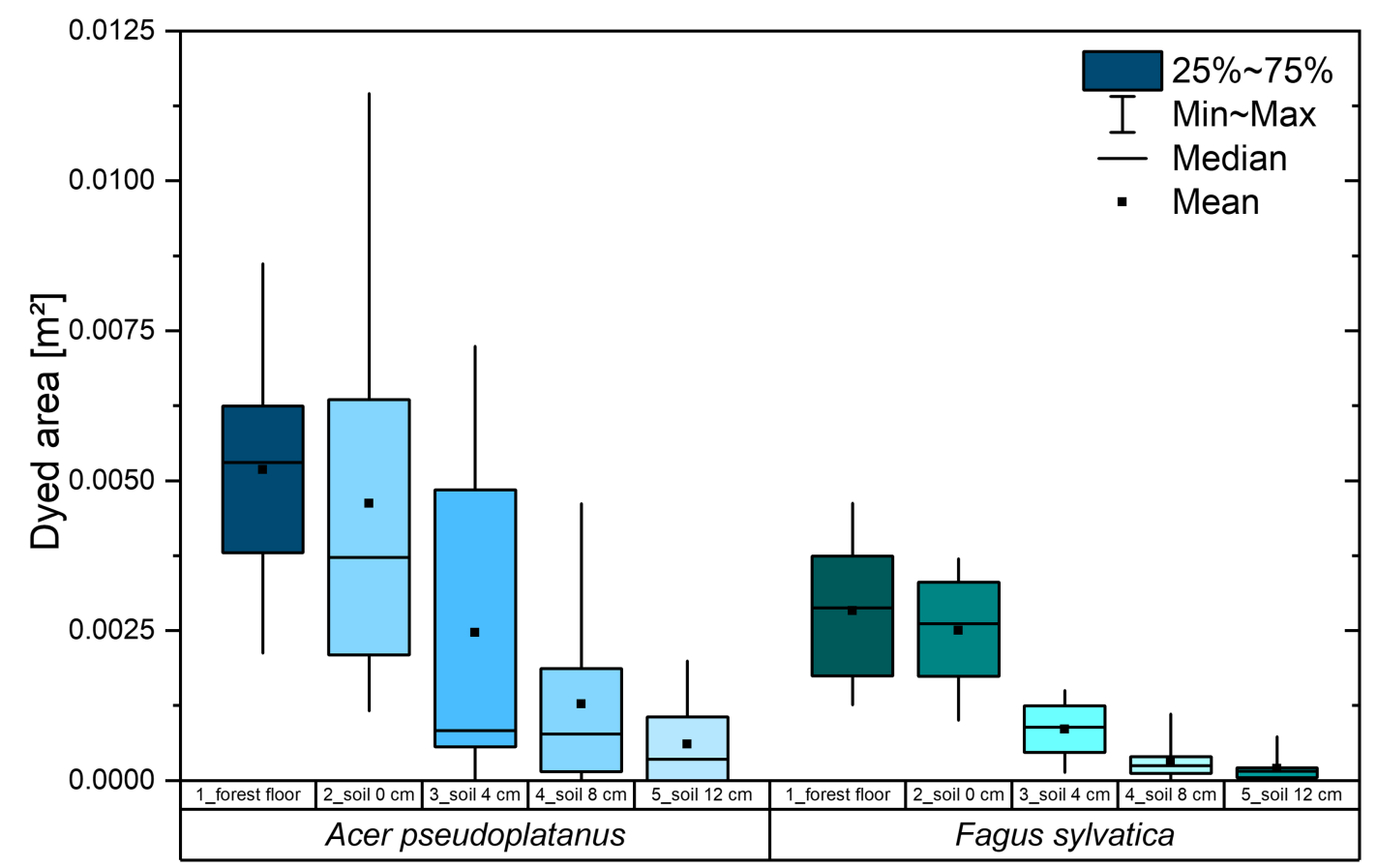

FIGURE 6 Brilliant Blue-dyed areas at the surface of the organic layer (forest floor) and the four mineral soil depths around the trunk base of sycamore maple (Acer pseudoplatanus L.) and European beech (Fagus sylvatica L.). Data were derived from eight sectors around each trunk

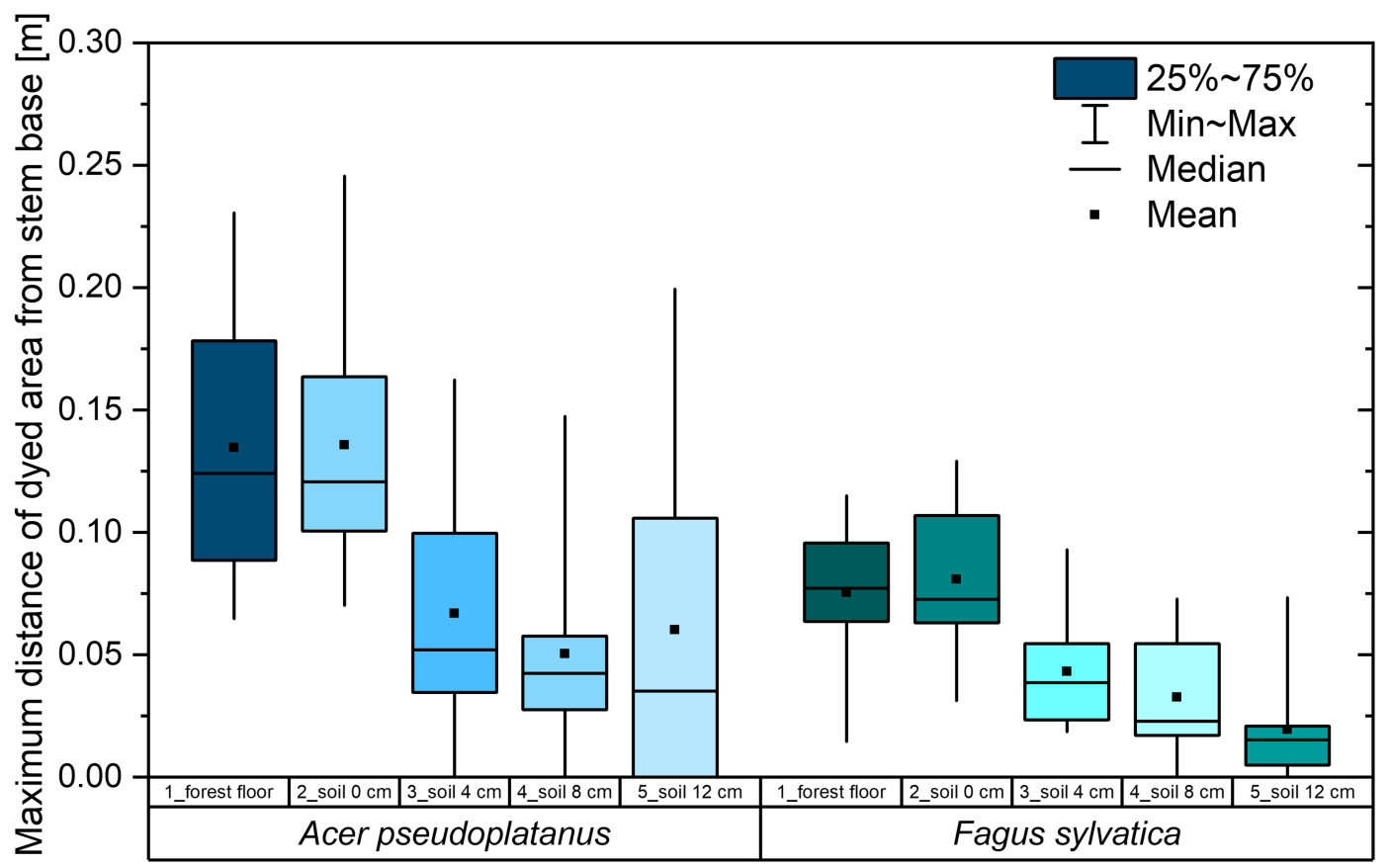

FIGURE 7 Maximum distance of Brilliant Blue-dyed areas at the surface of the organic layer (forest floor) and the four mineral soil depths around the trunk base of sycamore maple (Acer pseudoplatanus L.) and European beech (Fagus sylvatica L.). Data were derived from eight sectors around each trunk

In general, flow pattern were preferentially observed on surfaces of strong coarse roots at the base of the tree before entering the soil. Our results on SF patterns across the trunk, location and extent of infiltration areas, and maximum distances from the stem within an SF impact were still traceable and disprove a general relationship between SF pathways and infiltration areas. We can only speculate about the underlying processes; however, we assume that this discrepancy is related to the abundance, morphology and 'run-off' 
properties of the coarse roots girding the stems. Preferential flow along the surface of coarse roots was observed not only in the present study but also by Spencer and van Meerveld (2016) using Brilliant Blue and by Guo et al. (2020) applying geophysical techniques. Practical implications might relate to a more accurate positioning of soil moisture sensors for the monitoring of SF-induced water dynamics advocating an installation in close vicinity to relevant coarse roots. Areas with highly concentrated water influx and short-term water saturation might be hotspots of denitrification and other anaerobic biogeochemical processes, thus potentially affecting the $\mathrm{C}$ and nutrient cycling.

\subsection{Patterns of fine root distribution and soil $\mathrm{pH}$}

The median values of fine root biomass across eight sections and four soil depths vary between 1.27 and $6.00 \mathrm{~g} \mathrm{DW}$ for maple and between 0.52 and $5.84 \mathrm{~g} \mathrm{DW}$ for beech. Because of the differing dry masses of dyed and undyed forest floor and fine soil material, median fine root densities were normalized to $1 \mathrm{~g}$ of forest floor or soil material, covering ranges between 2.26 and 30.04 for maple with minimum and maximum $(\mathrm{min} / \mathrm{max})$ values between 1.17 and $64.29 \mathrm{mg} \mathrm{DW} \mathrm{g}$ soil $^{-1}$ (Figure S1). Corresponding values for beech exhibit median values of 1.00-36.02 and $\mathrm{min} / \mathrm{max}$ values of $0.42-81.80 \mathrm{mg} \mathrm{DW} \mathrm{g} \mathrm{soil}^{-1}$. In case of maple, there is a slight tendency of higher fine root densities within colour-dyed zones (forest floor and 0- to 4-cm soil depth, Figure S1); however, for beech, this trend is inconclusive. Thus, areas close to the stem receiving high SF amounts are not associated with higher fine root densities. One explanation might be that these locations are dominated by coarse roots.

Median soil pH values vary between 4.14 and 5.19 for maple and between 3.82 and 5.23 for beech (Figure S2). For both trees, highest $\mathrm{pH}$ values were detected in the forest floor and decrease with increasing mineral soil depth. In case of beech, the median $\mathrm{pH}$ of the forest floor was 0.3 units higher in the colour-dyed forest floor than in the undyed soil, whereas for maple, median $\mathrm{pH}$ values were very much alike (Figure S2). Both the trend of higher $\mathrm{pH}$ values and no difference between dyed and undyed forest floor and mineral soil are contrary to our expectations and the results reported by Gersper and Holowaychuk (1971). Our observations likely point to high inputs of base cations derived from dust of the surrounding calcareous bedrock and loess via SF, hence buffering the acidity associated with the incoming rainfall (Staelens, De Schrijver, \& Verheyen, 2007).

\section{4 | CONCLUSIONS AND FURTHER RESEARCH DIRECTIONS}

The 'passive dye' technique, which we applied in this study, differs from common colour tracer experiments, where stems are actively and homogeneously sprinkled with large amounts of colour tracer solution. Here, the trunk area was dye stained in advance, and SF patterns were visually quantified following natural rain events. Our results point to spatially restricted SF pathways on the tree trunks, exhibiting smaller washed-off areas for sycamore maple compared with European beech. The assumption of symmetric distribution of SF at the surface of the tree trunk appears unrealistic. For the integrated rainfall events and for both tree individuals, effective bark surface to a height of $1.5 \mathrm{~m}$ that was washed off by SF amounted to $\leq 15 \%$ and $\leq 39 \%$ for maple and beech, respectively. However, these differences between both tree species do not relate to the magnitude of infiltration areas at the soil surface, suggesting a strong effect of coarse root abundance and run-off properties on the funnelling of SF water. The infiltration area of SF at the trunk base is smaller than the BA, accounting for only $17 \%$ of the BA for beech and for $30 \%$ for maple. Thus, the effective infiltration area is smaller than currently anticipated corroborating the highly localized input of SF. For beech, colour-stained areas were restricted to a maximum extension of $0.12-\mathrm{m}$ distance from the stem and of $0.23 \mathrm{~m}$ for maple; thus, monitoring approaches that aim to investigate SF-induced soil water dynamics should consider these distances for the positioning of soil moisture probes. The outcome of this study might contribute to our understanding on hydrological and biogeochemical interlinkages between the surface and subsurface of the CZ. However, further research questions are: How do effective and hence active infiltration areas scale with tree diameter and projected canopy area? Are infiltration areas persistent across varying precipitation events? Will infiltration areas be more affected by tree species (interspecific) or by variability in tree morphology of the same species (intraspecific)? Which properties of tree trunks, in particular at the transition between coarse roots and soil, affect the development of infiltration areas most intensely? How to quantify these ecohydrological traits, and how does the abundance of epiphytic mosses at the tree trunk modify SF patterns?

\section{ACKNOWLEDGEMENTS}

The work was supported by the Collaborative Research Centre AquaDiva (CRC 1076 AquaDiva) of the Friedrich Schiller University Jena funded by the Deutsche Forschungsgemeinschaft. We thank the Hainich CZE site manager Robert Lehmann for providing rainfall data of the climate station 'Heuberg'. The authors gratefully acknowledge the help of Dr Karin Potthast during the field sampling campaign. We thank the two anonymous reviewers for their highly valuable comments that substantially improved the manuscript.

\section{CONFLICT OF INTERESTS}

None.

\section{DATA AVAILABILITY STATEMENT}

The data that support the findings of this study are available from the corresponding author upon reasonable request.

\section{ORCID}

Alexander Tischer (i) https://orcid.org/0000-0003-2923-8330

Beate Michalzik (D) https://orcid.org/0000-0001-7858-1771 


\section{REFERENCES}

Barbier, S., Balandier, P., \& Gosselin, F. (2009). Influence of several tree traits on rainfall partitioning in temperate and boreal forests: A review. Annals of Forest Science, 66, 602-1-602-11. https://doi.org/10.1051/ forest/2009041

Buttle, J. M., Toye, H. J., Greenwood, W. J., \& Bialkowski, R. (2014). Stemflow and soil water recharge during rainfall in a red pine chronosequence on the Oak Ridges Moraine, southern Ontario, Canada. Journal of Hydrology, 517, 777-790. https://doi.org/10.1016/ j.jhydrol.2014.06.014

Carlyle-Moses, D. E., S'i, I., Germer, S., Llorens, P., Michalzik, B., Nanko, K., ... Levia, D. F. (2018). Expressing stemflow commensurate with its ecohydrological importance. Advances in Water Resources, 121, 472-479. https://doi.org/10.1016/j.advwatres.2018.08.015

Dunkerley, D. (2014). Stemflow on the woody parts of plants: Dependence on rainfall intensity and event profile from laboratory simulations. Hydrological Processes, 28, 5469-5482. https://doi.org/10. 1002/hyp.10050

Flury, M., \& Flühler, H. (1995). Tracer characteristics of Brilliant Blue FCF. Soil Science Society of America Journal, 59, 22-27. https://doi.org/10. 2136/sssaj1995.03615995005900010003x

Friesen, J. (2020). Flow pathways of throughfall and stemflow through the subsurface. In I. T. van Stan, E. Gutmann, \& J. Friesen (Eds.), Precipitation partitioning by vegetation (pp. 215-227). Cham: Springer International Publishing. https://doi.org/10.1007/978-3-030-29702-2_13

Friesen, J., \& van Stan, J. T. (2019). Early European observations of precipitation partitioning by vegetation: A synthesis and evaluation of 19 th century findings. Geosciences, 9, 1-20, 423. https://doi.org/10.3390/ geosciences9100423

Frischbier, N., Tiebel, K., Tischer, A., \& Wagner, S. (2019). Small scale rainfall partitioning in a European beech forest ecosystem reveals heterogeneity of leaf area index and its connectivity to hydro- and atmosphere. Geosciences, 9, 1-23, 393. https://doi.org/10.3390/ geosciences9090393

Gersper, P. L., \& Holowaychuk, N. (1971). Some effects of stem flow from forest canopy trees on chemical properties of soils. Ecology, 52, 691-702. https://doi.org/10.2307/1934160

Guo, L., \& Lin, H. (2016). Critical zone research and observatories: Current status and future perspectives. Vadose Zone Journal, 15, 1-14. https:// doi.org/10.2136/vzj2016.06.0050

Guo, L., Mount, G. J., Hudson, S., Lin, H., \& Levia, D. (2020). Pairing geophysical techniques improves understanding of the near-surface Critical Zone: Visualization of preferential routing of stemflow along coarse roots. Geoderma, 357, 1-12, 113953. https://doi.org/10.1016/ j.geoderma.2019.113953

Jackson, N. A., Wallace, J. S., \& Ong, C. K. (2000). Tree pruning as a means of controlling water use in an agroforestry system in Kenya. Forest Ecology and Management, 126, 133-148. https://doi.org/10.1016/ S0378-1127(99)00096-1

Johnson, M. S., \& Lehmann, J. (2006). Double-funneling of trees. Stemflow and Root-Induced Preferential Flow. Écoscience, 13, 324-333. https:// doi.org/10.2980/i1195-6860-13-3-324.1

Küsel, K., Totsche, K. U., Trumbore, S. E., Lehmann, R., Steinhäuser, C., \& Herrmann, M. (2016). How deep can surface signals be traced in the critical zone? Merging biodiversity with biogeochemistry research in a central German Muschelkalk landscape. Frontiers in Earth Science, 4, 1-18. https://doi.org/10.3389/feart.2016.00032

Levia, D. F., \& Germer, S. (2015). A review of stemflow generation dynamics and stemflow-environment interactions in forests and shrublands. Reviews of Geophysics, 53, 673-714. https://doi.org/10.1002/ 2015RG000479
Liang, W.-L., K'i, K., \& Mizuyama, T. (2011). Soil water dynamics around a tree on a hillslope with or without rainwater supplied by stemflow. Water Resources Research, 47, 1-16, 161. https://doi.org/10.1029/ 2010WR009856

Metzger, J. C., Schumacher, J., Lange, M., \& Hildebrandt, A. (2019). Neighbourhood and stand structure affect stemflow generation in a heterogeneous deciduous temperate forest. Hydrology and Earth System Sciences Discussions, 1-35. https://doi.org/10.5194/hess2019-336

Metzger, J. C., Wutzler, T., Dalla Valle, N., Filipzik, J., Grauer, C., Lehmann, R., ... Hildebrandt, A. (2017). Vegetation impacts soil water content patterns by shaping canopy water fluxes and soil properties. Hydrological Processes, 31, 3783-3795. https://doi.org/10.1002/hyp.11274

Schwärzel, K., Ebermann, S., \& Schalling, N. (2012). Evidence of doublefunneling effect of beech trees by visualization of flow pathways using dye tracer. Journal of Hydrology, 470-471, 184-192. https://doi.org/ 10.1016/j.jhydrol.2012.08.048

Spencer, S. A., \& van Meerveld, H. J. (2016). Double funnelling in a mature coastal British Columbia forest: Spatial patterns of stemflow after infiltration. Hydrological Processes, 30, 4185-4201. https://doi.org/10. 1002/hyp.10936

Spies, T. A. (1998). Forest structure: A key to the ecosystem. In J. A. Trofymow \& A. MacKinnon (Eds.), Workshop on Structure, Process, and Diversity in Successional Forests of Coastal British Columbia. February 17-19, 1998, 72/2 (pp. 34-39). Pullman, WA: Washington State University Press.

Staelens, J., De Schrijver, A., \& Verheyen, K. (2007). Seasonal variation in throughfall and stemflow chemistry beneath a European beech (Fagus sylvatica) tree in relation to canopy phenology. Canadian Journal of Forest Research, 37, 1359-1372. https://doi.org/10.1139/X07-003

van Stan JT (2019) On the relevance of stemflow: An argument against funneling ratios and for a return to scaled flux-per-unit-area metrics, https://www.essoar.org/doi/10.1002/essoar.10501227.1

van Stan, J. T., \& Stubbins, A. (2018). Tree-DOM: Dissolved organic matter in throughfall and stemflow. Limnology and Oceanography Letters, 3, 199-214. https://doi.org/10.1002/lol2.10059

Tanaka, T., Taniguchi, M., \& Tsujimura, M. (1996). Significance of stemflow in groundwater recharge. 2: A cylindrical infiltration model for evaluating the stemflow contribution to groundwater recharge. Hydrological Processes, 10, 81-88. https://doi.org/10.1002/(SICl)1099-1085 (199601)10:1<81::AID-HYP302>3.0.CO;2-M

Voigt, G. K. (1960). Distribution of rainfall under forest stands. Forest Science, 6, 2-10. https://doi.org/10.1093/forestscience/6.1.2

\section{SUPPORTING INFORMATION}

Additional supporting information may be found online in the Supporting Information section at the end of this article.

How to cite this article: Tischer A, Michalzik B, Lotze R. Nonuniform but highly preferential stemflow routing along bark surfaces and actual smaller infiltration areas than previously assumed: A case study on European beech (Fagus sylvatica L.) and sycamore maple (Acer pseudoplatanus L.).. Ecohydrology. 2020;13:e2230. https://doi.org/10.1002/eco. 2230 